\title{
Pengaruh Program K3 Terhadap Produktivitas Kerja pada Operator Alat Berat di PT BJTI Kota Surabaya
}

\author{
Friska Ayu*, Denis Fidita K.**, Muslikha Nourma R.* \\ "Program Studi D-IV Keselamatan dan Kesehatan Kerja, Fakultas Kesehatan, Unusa \\ **Program Studi S1 Manajemen, Fakultas Ekonomi dan Bisnis, Unusa \\ e-mail: friskayuligoy@unusa.ac.id \& denisfk@unusa.ac.id
}

\begin{abstract}
More than 2 million people/years died due to work accidents and occupational disease (ILO, 2010), while at Indonesia showed every 7 second work accident was occurs. BJTI Port is a port service provider company that carries out activities as a port terminal operator. Heavy equipment operator is one of the high-risk jobs, therefore this company must arrange work program that support the occupational health and safety management implementation at workplace through Safety Culture Implementation. Analyze Influence Occupational Health and Safety Program to Productivity of Work to Heavy Equipment Worker at PT Berlian Jasa Terminal Indonesia Surabaya is the aim of this research. Total samples of 52 workers, taken by the total sampling method. Data related to respondent characteristics like productivity of worker and OHS Program obtained from direct observation to the field and interviews with all workers. The research results showed that as many as heavy equipment operators $(55,7 \%)$ had high productivity. The statistical test using ordinal regression test indicate that there is an influence between the OHS Program with Productivity of Work to Heavy Equipment Operator at BJTI Port $(0,000<0,05)$. Implementation of OHS Program at BJTI Port was good and need to be maintained, if possible, it can be improved by increasing the competency of OHS Supervisors and OHS management accordance with OHS regulations. In addition its necessary to conduct surveillance of $\mathrm{OHS}$ devices, especially in areas that are rarely traversed by $\mathrm{OHS}$ supervisor.
\end{abstract}

Keywords: productivity of work, OHS program, heavy equipment operator

\section{PENDAHULUAN}

Program keselamatan dan kesehatan kerja (K3) telah menjadi hal yang sangat penting untuk dipertimbangkan, karena manajemen K3 tidak hanya menjadi tanggung jawab bagian SDM perusahaan namun juga tanggung jawab semua pihak yang ada dalam perusahaan. Beberapa manfaat dengan diterapkannya manajemen K3 di tempat kerja yakni (1) meningkatnya efisiensi dan kualitas tenaga kerja yang lebih sehat, (2) produktivitas meningkat karena berkurangnya hari kerja yang hilang, (3) pengeluaran untuk pengobatan dan asuransi jiwa menurun, dan (4) meningkatnya reputasi perusahaan ${ }^{[2]}$.

Hasil penelitian yang dilakukan oleh Supriyan pada studi kasus proyek pembangunan Ceng- kareng Business City Lot 5 dengan sasaran 80 orang pekerja proyek menunjukkan bahwa $87,25 \%$ responden menyatakan penerapan manajemen K3 sudah diterapkan dengan baik dan sebesar $80 \%$ para pekerja setuju bahwa budaya K3 di lokasi proyek sudah berlangsung dengan baik $^{[3]}$. Hasil uji menggunakan regresi linier menunjukkan bahwa budaya K3 memiliki pengaruh signifikan dalam memengaruhi produktivitas kerja pekerja proyek dalam proyek Cengkareng Business City Lot 5. Hasil penelitian ini sejalan dengan penelitian yang dilakukan oleh Nia Malinasari (2015) bahwa penerapan program K3 di Lingkungan kerja PT Pembangkitan Jawa-Bali berpengaruh signifikan terhadap peningkatan produktivitas karyawan ${ }^{[4]}$. 
Semakin baik penerapan program K3 maka semakin baik pula produktivitas karyawannya, begitu sebaliknya. Melalui penerapan budaya K3 yang berkelanjutan, diharapkan mampu menurunkan tingkat kecelakaan kerja dan mampu meningkatkan semangat kerja karyawan. Menurut Ramli bahwa tenaga kerja yang terjamin keamanan dan kesehatannya maka akan bekerja lebih produktif sehingga hal ini akan mendukung keberhasilan dalam pembangunan perusahaan ${ }^{[5]}$.

Setiap tempat kerja memiliki potensi dan risiko bahaya bagi tenaga kerjanya, salah satunya adalah badan usaha penyelenggara jasa pelabuhan. PT Berlian Jasa Terminal Indonesia (PT BJTI) merupakan salah satu anak perusahaan PT Pelabuhan Indonesia III yang mana adalah badan usaha milik negara selaku penyelenggara jasa pelabuhan yang melakukan aktivitas sebagai port terminal operator terhitung sejak awal Januari 2002 dengan fokus usaha pelayanan jasa cargo and container handling pada terminal konvensional, di mana perusahaan tersebut telah menerapkan Sistem Manajemen K3.

Aktivitas pekerjaan yang banyak dilakukan di luar ruangan, melihat kondisi lingkungan serta proses kerja yang sangat rawan dan berisiko tinggi terhadap kecelakaan kerja maka perusahaan PT BJTI ini harus bertanggung jawab dalam memberikan perlindungan kepada para pekerjanya dengan menerapkan budaya K3 di tempat kerja. Keberhasilan suatu perusahaan tergantung dari produktivitas kerja pekerjanya. Oleh karena itu, penelitian itu bertujuan untuk menganalisis pengaruh program K3 terhadap produktivitas kerja pada operator alat berat di PT BJTI Kota Surabaya.

\section{METODE PENELITIAN}

Desain penelitian ini termasuk observasional analitik dengan rancangan cross sectional study. yakni suatu rancangan penelitian untuk mempelajari dinamika korelasi antara faktorfaktor risiko, dengan cara pendekatan observasi atau pengumpulan data sekaligus pada suatu saat $^{5}$. Dalam hal ini adalah program K3 menjadi variable independent dan produktivitas kerja sebagai variable dependent.

Populasi dalam penelitian ini adalah seluruh operator alat berat di PT BJTI Kota sebanyak 52 orang yang terbagi dalam tiga shift. Besaran sample sebanyak 52 orang yang ditarik dengan metode accidental sampling. Pengumpulan data terbagi dua yakni data primer dan data sekunder. Data primer diperoleh dengan mendapatkan data/informasi langsung dari para pekerja di PT BJTI yang menjadi responden pada saat wawancara maupun melakukan observasi, sedangkan data sekunder diperoleh melalui pihak manajemen perusahaan maupun telah kepustakaan untuk menunjang penelitian. Data yang diperoleh kemudian dianalisis menggunakan program SPSS.

\section{HASIL DAN PEMBAHASAN}

\section{A. Karakteristik Responden}

Tabel 1 Distribusi Karakteristik Individu pada Operator Alat Berat di PTBJTI Kota Surabaya

\begin{tabular}{|l|l|r|r|}
\hline $\begin{array}{c}\text { Karakteristik } \\
\text { Responden }\end{array}$ & \multicolumn{1}{|c|}{ Kategori } & n & \multicolumn{1}{|c|}{$\%$} \\
\hline \multirow{2}{*}{$\begin{array}{l}\text { Tingkat } \\
\text { pendidikan }\end{array}$} & SMP & 2 & 3.8 \\
\cline { 2 - 4 } & SMA & 41 & 78.8 \\
\cline { 2 - 4 } & PT & 9 & 17.3 \\
\hline \multirow{2}{*}{$\begin{array}{l}\text { Bagian } \\
\text { operator }\end{array}$} & Operator angkat (HMC, RTG, RS) & 29 & 56.0 \\
\cline { 2 - 4 } Shift kerja & Operator angkut (FL dan HT) & 23 & 44.0 \\
\cline { 2 - 4 } & $07.30-15.30$ & 18 & 34.6 \\
\cline { 2 - 4 } & $15.30-23.30$ & 23 & 44.2 \\
\cline { 2 - 4 } & $23.30-07.30$ & 11 & 21.2 \\
\hline \multirow{3}{*}{ Masa kerja } & $\geq 5$ tahun & 32 & 61.5 \\
\cline { 2 - 4 } & $<5$ tahun & 20 & 38.5 \\
\hline \multirow{2}{*}{ Produktivitas } & Produktivitas kerja tinggi & 37 & 71.1 \\
\cline { 2 - 4 } & Produktivitas kerja sedang & 11 & 21.2 \\
\cline { 2 - 4 } & Produktivitas kerja rendah & 5 & 7.7 \\
\hline \multirow{2}{*}{ Program K3 } & Ada dan tersosialisasi dengan baik & 36 & 69.23 \\
\cline { 2 - 4 } & Ada dan jarang disosialisasikan & 15 & 28.85 \\
\cline { 2 - 4 } & Ada dan tidak pernah disosialisasikan & 1 & 1.92 \\
\hline & Jumlah & 52 & 100.0 \\
\hline
\end{tabular}

Sumber: Data Primer, 2019 
Data Tabel 1 menunjukkan distribusi karakteristik individu pada pekerja bongkar muat di PT BJTI Kota Surabaya, dari 52 orang pekerja yang menjadi responden dalam penelitian ini, sebagian besar tingkat pendidikannya adalah SMA sebanyak 41 orang $(78,8 \%)$ dan sisanya sebanyak 2 orang $(3,8 \%)$ berpendidikan SMP dengan masa kerja lebih dari 5 tahun sebanyak 32 orang $(61,5 \%)$ dan bagian yang paling dominan adalah operator alat angkat (HMC, RTG dan RS) yakni sebanyak 29 orang (56\%). Sistem manajemen K3 di PT BJTI telah terimplementasi dengan baik, sehingga penerapan program K3 di PT BJTI sudah dirasakan sangat baik oleh pekerja karena 36 orang pekerja $(69,23 \%)$ berpendapat bahwa program K3 telah tersosialisasikan dengan baik pada pekerja. Berdasarkan hasil penilaian produktivitas kerja yang dilakukan pada operator alat berat, sebanyak 37 orang $(71,1 \%)$ memiliki produktivitas kerja yang tinggi.

\section{B. Pengaruh Program K3}

Data Tabel 2 menunjukkan tentang uji pengaruh antara program $\mathrm{K} 3$ dengan produktivitas kerja pada operator alat berat di PT BJTI Kota
Surabaya. Dari 52 orang pekerja yang menjadi responden dalam kegiatan penelitian ini sebanyak 36 pekerja berpendapat bahwa program K3 di PT BJTI sudah tersosialisasi dengan baik dan sebanyak 30 orang $(83,3 \%)$ memiliki produktivitas kerja yang tinggi, 5 orang lainnya memiliki produktivitas kerja sedang $(14,0 \%)$ dan sisanya memiliki produktivitas kerja rendah $(2,7 \%)$. Hasil uji statistik menggunakan regresi ordinal menunjukkan bahwa terdapat pengaruh program K3 terhadap produktivitas kerja $(0,000<0,05)$ pada operator alat berat di PT BJTI.

Sumber daya manusia dengan tingkat produktivitas yang maksimal sangat dibutuhkan untuk mencapai tujuan perusahaan dan produktivitas menjadi salah satu poin utama bagi perusahaan. Produktivitas merupakan indikator utama bagi kemajuan sebuah perusahaan, sehingga peningkatan produktivitas pada semua bagian system. Faktor yang memengaruhi produktivitas kerja antara lain pekerjaan yang sesuai dengan latar belakang pendidikan, upah yang menarik, perlindungan kesehatan dan kesejahteraan dalam pekerjaan, lingkungan dan suasana kerja yang baik, serta jenjang karier dan pengembangan diri.

Tabel 2 Uji Pengaruh antara Program K3 dengan Produktivitas Kerja pada Operator Alat Berat di PTBJTI Kota Surabaya

\begin{tabular}{|c|c|c|c|c|c|c|c|c|c|}
\hline \multirow{3}{*}{\multicolumn{2}{|c|}{ Variabel Independen }} & \multicolumn{6}{|c|}{$\begin{array}{l}\text { Variabel Dependen } \\
\text { Produktivitas Kerja) }\end{array}$} & \multirow{3}{*}{$\mathbf{N}$} & \multirow{3}{*}{$\%$} \\
\hline & & \multicolumn{2}{|c|}{$\begin{array}{c}\text { Produktivitas } \\
\text { Kerja Tinggi }\end{array}$} & \multicolumn{2}{|c|}{$\begin{array}{l}\text { Produktivitas } \\
\text { Kerja Sedang }\end{array}$} & \multicolumn{2}{|c|}{$\begin{array}{l}\text { Produktivitas } \\
\text { Kerja Rendah } \\
\end{array}$} & & \\
\hline & & $\mathbf{n}$ & $\%$ & $n$ & $\%$ & $\mathrm{n}$ & $\%$ & & \\
\hline \multirow{3}{*}{$\begin{array}{l}\text { Program K3 } \\
\text { di Perusa- } \\
\text { haan }\end{array}$} & $\begin{array}{l}\text { Ada dan tersosialisa- } \\
\text { si dengan baik }\end{array}$ & 30 & 83.3 & 5 & 14.0 & 1 & 2.7 & 36 & 100 \\
\hline & $\begin{array}{l}\text { Ada dan Jarang di- } \\
\text { sosialisasikan }\end{array}$ & 7 & 46.7 & 5 & 33.3 & 3 & 20.0 & 15 & 100 \\
\hline & $\begin{array}{l}\text { Ada dan tidak per- } \\
\text { nah disosialisasikan }\end{array}$ & 0 & 0 & 1 & 100 & 0 & 0 & 1 & 100 \\
\hline \multicolumn{2}{|r|}{ Jumlah } & 37 & 71.1 & 11 & 21.2 & 5 & 7.7 & 52 & 100 \\
\hline
\end{tabular}

Sumber: Data Primer, 2019 
Setiap tempat kerja memiliki potensi dan risiko bahaya bagi tenaga kerja, salah satunya adalah badan usaha penyelenggara jasa pelabuhan. PT BJTI merupakan salah satu anak perusahaan PT Pelabuhan Indonesia III yang mana adalah badan usaha milik negara selaku penyelenggara jasa pelabuhan yang melakukan aktivitas sebagai port terminal operator terhitung sejak awal Januari 2002 dengan fokus usaha pelayanan jasa cargo and container handling pada terminal konvensional, di mana perusahaan tersebut telah menerapkan sistem manajemen $\mathrm{K} 3$.

Angka kecelakaan kerja mencapai lebih dari 100.000 kasus/tahun, jika dilihat secara sektor usaha, angka kecelakaan kerja di sektor jasa konstruksi paling tinggi dibandingkan dengan sektor lainnya. Kemenaker RI (2011) mencatat kecelakaan kerja masih didominasi bidang jasa konstruksi $(31,9 \%)$, disusul sektor industri manufaktur $(31,6 \%)$ dan transportasi $(9,3 \%)$. Upaya yang dilakukan untuk menekan angka kecelakaan kerja adalah dengan penerapan Sistem manajemen K3 (SMK3), dengan diterapkannya SMK3 di sebuah perusahaan, harapannya adalah angka kecelakaan kerja dapat ditekan melalui program K3. Program keselamatan dan kesehatan kerja (K3) telah menjadi hal yang sangat penting untuk dipertimbangkan, karena manajemen K3 tidak hanya menjadi tanggung jawab bagian SDM perusahaan akan tetapi menjadi tanggung jawab semua pihak yang ada dalam perusahaan.

Program kesehatan dan keselamatan kerja disusun dengan memperhatikan aspek berikut.

\section{Upaya pencegahan (prevention)}

Upaya pencegahan (prevention) merupakan upaya yang dilakukan untuk mengendalikan potensi bahaya yang ada di lingkungan kerja. Adapun upaya yang dapat dilakukan yakni dengan mengadakan sosialisasi potensi bahaya di tempat kerja, penyuluhan kesehatan secara langsung kepada pekerja, memasang safety poster dan safety sign di setiap sudut tempat kerja untuk mengingatkan pekerja agar lebih berhati-hati dalam bekerja.

\section{Upaya pengobatan (kuratif)}

Upaya kuratif yang merupakan salah satu upaya yang dilakukan untuk meminimalkan risiko dari paparan potensi bahaya di lingkungan kerja melalui upaya penanganan kecelakaan.

Standar internasional mengenai sistem manajemen kesehatan dan keselamatan kerja, PT BJTI telah memiliki sertifikat OHSAS 18001. OHSAS 18001 adalah suatu standar internasional untuk sistem manajemen kesehatan dan keselamatan kerja yang bertujuan untuk mengelola aspek kesehatan dan keselamatan kerja (K3) daripada keamanan produk (OHSAS 18001). OHSAS 18001 menyediakan kerangka bagi efektivitas manajemen K3 termasuk kesesuaian dengan peraturan perundang-undangan yang diterapkan pada aktivitas-aktivitas karyawan dan mengenali adanya bahaya-bahaya yang timbul. Berikut ini adalah beberapa manfaat pelaksanaan sistem manajemen kesehatan dan keselamatan kerja di bawah standar OHSAS 18001.

a. Perlindungan terhadap kesehatan dan keselamatan kerja karyawan

b. Mengurangi risiko kecelakaan

c. Motivasi karyawan lebih tinggi

d. Pengurangan biaya operasi dan biaya kecelakaan kerja

e. Meningkatkan citra perusahaan

\section{Pengaruh Program K3 terhadap Produktivitas Kerja pada Operator Alat Berat di PTBJTI}

Kesehatan dan keselamatan kerja (K3) merupakan salah upaya yang dilakukan untuk mene- 
kan angka kecelakaan kerja dan penyakit akibat kerja. Tujuan penerapan K3 adalah sebagai berikut. (1) Melindungi tenaga kerja atas hak keselamatannya dalam melakukan pekerjaan untuk kesejahteraan hidup dan meningkatkan produksi serta produktivitas nasional. (2) Menjamin keselamatan setiap orang lain yang berada di tempat kerja. (3) Sumber produksi dipelihara dan dipergunakan secara aman dan efisien.

Perusahaan yang menjalankan roda bisnisnya dengan aman (safety business), biasanya sangat memperhatikan kesehatan karyawan, hal ini berarti perusahaan menganggap karyawan merupakan salah satu asset perusahaan yang wajib dilindungi. Salah satu upaya yang dilakukan adalah dengan menerapkan sistem manajemen K3 (SMK3) di perusahaan, karena dengan menerapkan K3 maka perusahaan tersebut akan menyusun program K3 yang harapannya dapat meningkatkan produktivitas pekerja.

Hasil penelitian ini menunjukkan bahwa program K3 yang sudah diterapkan di PT Berlian Jasa Terminal Indonesia Kota Surabaya memiliki pengaruh terhadap produktivitas kerja para operator alat berat. Hal ini dikarenakan program K3 yang ada di PT BJTI penerapannya dianggap sudah sangat baik oleh para pekerja, karena program $\mathrm{K} 3$ sudah berjalan secara rutin dan para pekerja telah mendapatkan manfaat dari penerapan K3 di tempat kerja. Para pekerja terutama operator alat berat lebih berhati-hati dan mawas diri ketika bekerja, sebelum memasuki area kerja biasanya dilakukan kegiatan safety meeting untuk mengingatkan kembali para pekerja tentang potensi dan risiko bahaya yang dapat terjadi saat bekerja.

Hasil penelitian ini sejalan dengan penelitian yang dilakukan oleh Rahman (2014) yang menyatakan bahwa terdapat peningkatan budaya K3 melalui penerapan program K3 akan berpenga- ruh terhadap peningkatan produktivitas kerja pada pekerja mekanik alat berat di Kalimantan Selatan. Selain itu, penelitian ini juga sejalan dengan penelitian yang dilakukan oleh Pangestu (2016) bahwa program keselamatan dan kesehatan kerja (K3) dan disiplin kerja memiliki pengaruh yang signifikan secara parsial dan simultan terhadap produktivitas kerja.

Produktivitas kerja seseorang dapat dipengaruhi oleh manajemen di tempat kerja hubungan antara tenaga kerja dengan pimpinan organisasi. Manajemen perusahaan yang baik adalah manajemen yang secara efisien mengatur mengenai sumber daya dan sistem kerja untuk mencapai peningkatan produktivitas. Komitmen pimpinan perusahaan untuk menerapkan SMK3 di perusahaannya merupakan salah satu upaya yang dilakukan untuk melakukan pengawasan terhadap karyawan agar lebih berhati-hati dalam bekerja sehingga dapat menekan kejadian kecelakaan kerja dan penyakit akibat kerja.

\section{SIMPULAN DAN SARAN}

\section{Kesimpulan}

Dari hasil penelitian yang telah dilakukan dapat disimpulkan sebagai berikut.

1. Dari hasil wawancara pada operator alat berat di PT BJTI terkait produktivitas kerja pada operator alat berat di PT BJTI Kota Surabaya menunjukkan bahwa sebagian besar para pekerja memiliki produktivitas kerja yang tinggi.

2. Terdapat pengaruh antara program K3 dengan produktivitas kerja pada operator alat berat di PT BJTI, karena pekerja yang memiliki produktivitas kerja yang tinggi adalah pekerja yang beranggapan bahwa program K3 yang ada di PT BJTI sudah tersosialisasikan dengan baik pada para pekerja. 


\section{Saran}

1. Bagi pekerja diharapkan untuk dapat meningkatkan kepatuhan dan kesadarannya untuk dapat bekerja secara hati-hati dan mematuhi segala peraturan yang berhubungan dengan K3 di tempat kerja dengan ataupun tanpa pengawasan dari pihak HSE perusahaan.

2. Bagi perusahaan sebaiknya mempertahankan program K3 yang telah dilaksanakan, jika mungkin dapat ditingkatkan dengan meningkatkan kompetensi pengawas dan pengelolaan K3 sesuai dengan regulasi, selain itu perlu melakukan pengawasan terhadap perangkat keselamatan dan kesehatan kerja terutama pada area yang jarang dilalui oleh pengawas lapangan.

\section{DAFTAR RUJUKAN}

Budaya Keselamatan Terjemahan Dokumen IAAC Safety Report 75-Insag-4. 2015. Safety Culture, Badan Pengawas Tenaga Nuklir, diakses tanggal 30 September 2018.

Hameed, A. dan Shela A. 2009. Impact of Design on Employees Productivity: A Case study of Banking Organizations of Abbottabad, Pakistan. Journal of Public Affairs, Administration, and Management, Volume 3 , Issue 1.

International Atomic Energy Agency. 1996. Quality Assurance for Safety in Nuclear Power Plants and Other Nuclear Installations, Code and Safety Guides Q1-Q14. Safety Series, No. 50-C/SGQ. Vienna, Austria: IAEA.

International Labour Organization. 2013. Promoting a Safe and Healthy Working Environment. Geneva, Switzerland: International Labour Office.
International Nuclear Safety Advisory Group. 1991. Safety Culture, Safety Series No. 75-INSAG-4, disitasi tanggal 23 September 2018. Vienna, Austria: IAEA.

Jackson, R.S.S. dan Werner, S. 2011. Pengelolaan Sumber Daya Manusia, Edisi Kesepuluh. Jakarta: Salemba Empat.

Kurniasih, D. dan Rachmadita, R. 2013. Pengukuran Budaya K3 pada Tingkat Non-Manajerial dengan Menggunakan Cooper's Reciprocal Safety Culture Model di PT X, Jurnal Politeknik Perkapalan. Universitas Negeri Surabaya Jurusan Teknik Desain dan Manufaktur.

Malinasri, N. 2016. Pengaruh Program Keselamatan dan Kesehatan Kerja (K3) dan Jaminan Sosial Terhadap Produktivitas Kerja Karyawan (Studi pada PJB UP Brantas Karangkates-Kab.Malang). Jurnal Ilmiah Mahasiswa Fakultas Ekonomi Bisnis. Malang: Universitas Brawijaya.

Ndraha, T. 2005. Teori Budaya Organisasi, Cetakan Pertama, PT Rineka Cipta, Jakarta.

Notoatmodjo, S. 2010. Metodologi Penelitian Kesehatan. Jakarta. Rineka Cipta.

Pangestu, A. 2016. Pengaruh Program Keselamatan dan Kesehatan Kerja (K3) dan Disiplin Kerja Karyawan Terhadap Produktivitas Kerja Karyawan.

Rahman, N. 2014. Pengaruh Budaya Kesehatan dan Keselamatan Kerja Terhadap Produktivitas Mekanik alat berat. Jurnal Intekna, Tahun XIV, No.1, Mei 2014.

Ramli, S. 2010. Sistem Manajemen Keselamatan dan Kesehatan Kerja OHSAS 18001. Jakarta: Dian Rakyat.

Setiawan, H. 2009. Pengaruh Budaya Organisasi dan Program Keselamatan dan Kesehatan Kerja (K3) pada Produktivitas Karyawan PT KAI Bandung. Jurnal Trikonomika, Volume 8, No.1 Juni. 
Sugiyono. 2016. Metode Penelitian Kuantitatif, Kualitatif, dan RひD. Bandung: Alfabet.

Suma'mur, P. K. 2012. Higiene Perusahaan dan Kesehatan Kerja (HIPERKES). Jakarta: Sagung Seto.
Suprian, D. 2016. Pengaruh Manajemen K3 dan Budaya K3 Terhadap Kinerja Pekerja Proyek (Studi Kasus Proyek Pembangunan Cengkareng Business City Lot 5). Jurnal Jurusan Teknik Sipil Politeknik Negeri Jakarta. Depok: Kampus UI. 